The mechanism for the air in the mediastinum is suggested as being due to rupture of marginal pulmonary alveoli, allowing the development of pulmonary interstitial emphysema. This then tracks through the fascial planes at the lung hilum, and from there into the mediastinum and neck. There was no obvious underlying lung disease in our patient, and no further investigations were indicated. His lymphocytosis may have been secondary to a coryzal illness from which he was recovering at the time; upper respiratory tract infections have been associated with this condition. ${ }^{4}$ The relatively benign course and rapid recovery shown by the patient was in keeping with the findings of others, ${ }^{5}$ and recurrence is very unusual. ${ }^{4}$

We thank Dr G Terry for permission to report this case.

${ }^{1}$ Munsell WP. Pneumomediastinum. f $A M A$ 1967;202:689-93.

2 Macklin MT, Macklin CC. Malignant interstitial emphysema of the lungs and mediastinum as an important occult complication in many respiratory disease and other conditions: an interpretation of the clinical literature in the light of laboratory experiment. Medicine (Baltimore) $1944 ; 23: 281-358$.

${ }^{3}$ Hillman KM. Severe coughing and pneumoperitoneum. $\mathrm{Br} \mathrm{Med} \mathcal{F} 1982$; $285: 1085$.

+ Yellin A, Gapany-Gapanavicius M, Lieberman Y. Spontaneous pneumoperitoneum: is it a rare cause of chest pain ? Thorax $1983 ; 38: 383-5$.

${ }^{5}$ Ravez P, Wackenier P, Robience Y. Spontaneous mediastinal emphysema Report of 2 cases. (In French.) Rev Med Brux 1981;2:961-3.

(Accepted 25 fanuary 1984)

Departments of Medicine and Radiology, Dryburn Hospital, Durham

C J PACKHAM, BMEDSCI, BM, senior house officer in general medicine G C STEVENSON, MB, BS, registrar in radiology

$S$ HADLEY, MB, CHB, senior house officer in general medicine

Correspondence to: Dr C J Packham, Department of Medicine, Newcastle General Hospital, Newcastle upon Tyne NE4 6BE.

\section{Hydatid false positive serological test results in malignancy}

Despite advances in radiology, ultrasound, and computed tomographic imaging techniques, diagnosis of hydatid disease still relies on serological tests to distinguish between a hydatid cyst and other, similar space occupying lesions. Serological tests, however, vary considerably in both sensitivity and specificity. This variability is multifactorial, dependent on the qualitative and quantitative differences in the test antigen used, the criterion (titre) for positivity, the location and viability of the cysts, and possibly the strain of the parasite concerned.

Reports of serological tests for hydatid giving false positive results in various malignant diseases appear regularly, suggesting antigenic similarity between Echinococcus granulosus and neoplasms ${ }^{1}$; a similar phenomenon occurs between bacteria and certain tumour cells. Kagan attributed these false positive reactions to autoantibodies which react with human host protein components found in hydatid fluid antigen. ${ }^{2}$ Norris was more specific ${ }^{3}$ : she attributed false positive complement fixation test reactions in patients with cancer to interaction of blood group $P$ substance in hydatid fluid ${ }^{4}$ with anti- $P_{1}$ antibody in sensitised patients. Norris raised the question whether neoplasms are associated with an increased susceptibility to sensitisation by the $P$ substance in hydatid cyst fluid used as test antigen in the Casoni skin test : the patients who developed the anti- $\mathrm{P}_{1}$ antibody after Casoni tests all had carcinoma.

We have used the indirect haemagglutination test and counterimmunoelectrophoresis to assess the frequency and nature of hydatid false positive reactions in patients with histologically confirmed cancer and tested the presence of anti- $\mathrm{P}_{1}$ antibodies.

\section{Materials, methods, and results}

A commercially available indirect haemagglutination test (Cellognost, Behringwerke) and counterimmunoelectrophoresis using a raw, high potency human hydatid fluid antigen were used to examine sera from 19 surgically confirmed cases of hydatid disease, 21 histologically confirmed cases of cancer (two each of oesophagus, lung, kidney, stomach, breast, and leukae- mia; one each of bile duct, prostate, cervix, liver, rectum, retina, buccal, Burkitt's, and Hodgkin's), and 22 normal controls. We also tested each serum sample for anti- $P_{1}$ antibodies using $P_{1}+$ and $P_{1}-$ sensitised cells. The table summarises the results.

Serological test responses to hydatid antigen

\begin{tabular}{|c|c|c|c|c|}
\hline Test group & No & No IHA positive & $\begin{array}{l}\text { No CIE } \\
\text { positive }\end{array}$ & $\begin{array}{l}\text { No with } \\
\text { anti-P } \\
\text { antibodies }\end{array}$ \\
\hline $\begin{array}{l}\text { Surgically confirmed cases of } \\
\text { hydatid } \\
\text { Histologically confirmed }\end{array}$ & 19 & $19(>1 / 64)$ & 19 & 1 \\
\hline $\begin{array}{l}\text { Histologically confirmed } \\
\text { cases of malignancy } \\
\text { Normal controls }\end{array}$ & $\begin{array}{l}21 \\
22\end{array}$ & $\begin{array}{l}5(1 / 8-1 / 256) \\
2(1 / 8-1 / 16)\end{array}$ & & $\begin{array}{l}2 \\
1\end{array}$ \\
\hline
\end{tabular}

IHA = Indirect haemagglutination. $\mathrm{CIE}=$ Counterimmunoelectrophoresis

Counterimmunoelectrophoresis was highly specific for hydatid disease, no false positive reactions being obtained either in cancer or in normal control sera. Four sera from patients with cancer (adenocarcinoma of bile duct, bronchial carcinoma, chronic myeloid leukaemia, hypernephroma) tested by indirect haemagglutination gave false positive results with low titres of $1 / 8$ $1 / 64$. Only serum from the one case of retinoblastoma gave a significantly high titre of $1 / 256$. The two false positive reactions in the normal control group were also in low titres of $1 / 8-1 / 16$. None of the five patients with cancer whose sera showed false positive reactions had anti- $P_{1}$ antibodies. Gel diffusion tests for antigenic similarity between hydatid and false positive cancer sera showed no precipitation lines of identity.

\section{Comment}

The reported antigenic similarity between $E$ granulosus and malignant cells is not proved. Seropositivity is often an idiosyncrasy of the test employed. Cross reactions may be due to the artefacts of the system as a result of immunochemically altered antigens; or they may be due to the presence of such non-immunoglobulins as $C$ reactive protein, which appears in the acute phase of many illnesses including malignancy and may precipitate with polysaccharide extracts of various micro-organisms. Interestingly, the positive titres in most of our hydatid false positive cases of cancer were of a low order whatever the test employed. In our laboratory a titre of $\geqslant 1 / 64$ in the indirect haemagglutination test is regarded as diagnostically positive for hydatidosis; hence the one case of retinoblastoma with a titre of $1 / 256$ in our series, and similarly high titres in other series, may have been due to concomitant hydatid disease. El Shareef et al found two such cases among 30 patients with hydatid disease of the liver. ${ }^{5}$ Even the low positive titres in the cancer sera may have been a result of previous exposure to $E$ granulosus ova in endemic areas of hydatid disease.

Norris's finding that strong anti- $P_{1}$ antibodies in sera may give false positive results in complement fixation tests for hydatid ${ }^{3}$ would seem to apply only to those patients with cancer who have had a Casoni skin test. As none of our patients with cancer had had skin tests for hydatidosis, it would again appear that the false positive low titres in some of them were due to some other non-specific antigen-antibody interactions.

We thank Mr Sassi Al Eyat, of the Jala Hospital blood bank, for his help in blood group serotyping and anti- $\mathrm{P}_{\mathbf{1}}$ antibody determinations.

1 van Knapen $\mathrm{F}$. Echinococcus granulosus infection and malignancy. $\mathrm{Br}$ Med $71980 ; 281: 195-6$

2 Kagan IG. A review of serological tests for the diagnosis of hydatid disease. Bull WHO 1968;38:25-37.

${ }^{3}$ Norris TJ. Blood group $\mathrm{P}_{1}$ : serological diagnosis of Echinococcus and carcinoma. Med f Aust $1965 ; \mathrm{i}: 792-4$

4 Cameron GL, Stavely JM. Blood group P substance in hydatid cyst fluids. Nature 1957;179:147-8.

5 El Shareef AM, Taguri S, Dar FK, Abdel GY. Serum polysaccharides in hydatid disease of liver and lung. Garyounis Medical fournal 1979;2: 31-3.

(Accepted 27 fanuary 1984)

Faculty of Medicine, University of Garyounis, Box 1451, Benghazi, Libya

F K DAR, PHD, professor of parasitology

M A BUHIDMA, MB, CHB, demonstrator in pathology

S A KIDWAI, PHD, lecturer in parasitology

Correspondence to: Professor F K Dar. 